\title{
Os deslimites da palavra de Manoel de Barros
}

\author{
The unlimits of the word of Manoel de Barros
}

\author{
GEYSIANE ANDRADE (D) \\ PUCRS, Porto Alegre, Rio Grande do Sul, Brasil.
}

\begin{abstract}
Resumo: Manoel de Barros se traduziu na liberdade e no encantamento dos versos, em um trabalho artesanal com as palavras. Na linguagem, construiu um infinito particular, onde desvela muito mais do que as belezas do Pantanal, mas a grandeza do homem e da vida, uma poesia contemporânea que dialoga com a tradição simbolista e moderna. Exemplo disso é $O$ livro das Ignorãças, no qual o autor apresenta seu percurso criativo e as origens de sua criação poética, transformando o ínfimo, o nada e as miudezas em pura poesia. Assim, este trabalho apresenta um pouco do projeto poético de Barros, especialmente no livro em questão, refletindo sobre seu processo criativo de acordo com algumas das teorias da criação poética.

Palavras-chaves: Poesia; Manoel de Barros; Lírica moderna; Criação poética.

Abstract: Manoel de Barros translated himself into the freedom and enchantment of the verses, in a handcrafted work with words. In language, he constructed a particular infinite, where he unveils much more than the beauties of Pantanal, but the greatness of man and life, contemporary poetry that dialogues with the symbolism and modern tradition. A great example is $O$ livro das Ignorãças, in which the author presents his creative journey and the origins of his poetic creation, transforming the tiny, the nothingness and the offal into pure poetry. Thus, this paper presents a little of the poetic project of Barros, especially in this book, reflecting on its creative process according to some poetic creation theories.
\end{abstract}

Keywords: Poetry; Manoel de Barros; Modern lyric; Poetic creation.

Entre as árvores, rios, pássaros, lagartos, besouros e formigas, Manoel de Barros contemplava as miudezas do Pantanal. O poeta mato-grossense criou um universo particular, onde congregava a natureza e as palavras, que se arranjavam de forma única até se transmutar em poesia. Divulgou seus primeiros poemas em 1937, porém com reconhecimento tardio apenas a partir dos anos 80 , sendo considerado um dos principais expoentes da poesia brasileira, aclamado até mesmo por Carlos Drummond de Andrade. Apesar de suas primeiras obras indicarem um tom mais impessoal, ligada às convenções poéticas ou à crítica à tradição literária do modernismo, a poesia de Manoel de Barros se transforma, assumindo características singulares que marcaram sua carreira. 
Entre sua fortuna crítica de largo espectro, destacam-se: Poemas concebidos sem pecado (1937), livro de estreia, Compêndio para uso dos pássaros (1960), ganhador do Prêmio Orlando Dantas Diário de Notícias; Gramática expositiva do chão (1966), que levou o Prêmio da Fundação Cultural do Distrito Federal; O guardador de águas (1989), vencedor do Prêmio Jabuti de Literatura; O livro das ignorãças (1993), Prêmio Alfonso Guimarães da Biblioteca Nacional; Livro sobre nada (1996), Prêmio Nestlé de Poesia; O fazedor de Amanhecer (2001), também congratulado com o Prêmio Jabuti, entre outras de grande importância para a literatura brasileira.

Tomando como objeto de estudo O livro das ignorãças (1993), percebese no projeto poético de Barros uma poesia contemporânea que dialoga com a tradição simbolista e moderna. De acordo com Paz (1996, p. 134), um dos elementos que distingue a modernidade de outras épocas é a crítica, "o novo se opõe ao antigo e essa oposição é a continuidade da tradição", ou seja, há uma ruptura com as vanguardas. Contudo, o poeta chegou a afirmar em entrevista ${ }^{1}$ que não havia intenção modernista ou política em seus primeiros livros, apesar de sua admiração por Oswald de Andrade, mas, para ele, foi um período de experiências, durante o qual buscava um estilo próprio. Até que, a partir das leituras de Rimbaud, finalmente, "escutou a cor de um passarinho", herdando sua liberdade e 'desorientação' dos versos.

1 Entrevista com Manoel de Barros. Palavra. Disponível: em: http://www.sesc.com.br/portal/site/palavra/dossie/ entrevista/entrevista $+\mathrm{com}+$ manoel + de + barros. Acesso em 19 jun. 2018.
Como principal legado, Manoel de Barros desenvolveu uma linguagem ímpar, com poesia que reflete sobre sua própria consciência criadora no desejo de retorno à pureza inicial da palavra e suas sinestesias, conferindo liberdade à ela proposto pelo Simbolismo e Modernismo -, além de desdobrar o sujeito poético em vários outros 'eus' e, principalmente, tornar o nada, o ínfimo e as insignificâncias como elementos principais de seu projeto poético.

Segundo Friedrich (1978), a poesia moderna traz uma perspectiva de anormalidade e dissonância, ou seja, se distancia das formas semânticas e estéticas romanescas, numa junção de incompreensibilidade e fascinação, gerando uma tensão que tende à inquietude do leitor. Nesse sentido, Barros inaugura um vocabulário próprio e nomeia sua sintaxe de "vanguarda primitiva", em uma simbiose entre poesia e natureza, na tentativa de trazer certa consciência anterior criadora. O livro das ignorãças apresenta todos esses aspectos em seu processo construtivo.

Em análise, é perceptível que o livro, na sua estética de divisão dos capítulos e escolha dos poemas, é uma espécie de história da criação, dividida em três partes: Uma didática da invenção, Os deslimites da palavra e Mundo pequeno. Como se fosse início, meio e fim (tal qual uma história e a vida), fala sobre seu fazer poético, a origem de suas palavras, em diálogo também com a criação do mundo (e do próprio mundo que cria em torno de sua poética).

O título do livro traz imediatamente o neologismo "ignorãças", referindo-se à ignorância das rãs. Ao comentar sobre a obra, Barros mencionou que "criar começa com a própria ignorância. É preciso ignorar para fazer acontecimentos. 
Poesia é sempre um refazer, um transfazer o mundo" (BARBOSA, 2003, p.59). Na sua visão, é necessário "desaprender um pouco o que aprendeu" e só assim ter um novo olhar sobre o mundo, como se fosse a primeira vez. A grafia do neologismo faz referência também ao modo de falar das pessoas mais simples, lembrando outras palavras populares, como "questã" (questão), "sustança" (sustância), "congestã" (congestão) e "distança" (distância). Já a simbologia da rã indica fertilidade, transformação, metamorfose e evolução ${ }^{2}$, tal qual é o conhecimento. E pode ainda fazer alusão ao "haikai da rã", do poeta japonês Matsuo Bashô. A estética dos haikais japoneses revela uma linguagem clara, trazendo o mais popular e um novo olhar para o mundo, com o ser humano integrado à natureza e a tudo que o cerca. Essa tendência influenciou os poetas modernistas brasileiros e também Manoel de Barros, que resgatou o elo entre o mundo natural, o sensível, o homem e seu cotidiano. Assim como Bashô, Barros reinventou a tradição à sua própria maneira.

Essa ideia de "desaprender" e "reaprender" fica explícita no poema II da primeira parte do livro, Uma didática da invenção:

II

Desinventar objetos. O pente, por exemplo. Dar ao

pente funções de não pentear.

Até que ele fique à

disposição de ser begônia. Ou uma gravanha.

Usar algumas palavras que ainda não tenham idioma

(BARROS, 1993, p. 11).

2 Cf. Dicionário dos símbolos. Disponível em: https:// www.dicionariodesimbolos.com.br/sapo/. Acesso em 22 jun. 2018.
É possível perceber a metalinguagem em relação à criação poética. Se antes de aprender é preciso desaprender, neste poema o autor também usa o prefixo des, no sentido de dar aos objetos uma nova função, ou seja, o prefixo não carrega exatamente seu sentido etimológico de negação ou oposição ("não aprender" ou "não inventar"), mas de ressignificação, um novo jeito de aprendizado e invenção que foge da ordem gramatical ou racional.

Essa desconstrução e desfamiliarização da linguagem se aproxima às teorias propostas pelo formalismo russo. Chklovski (1973, p. 45), um dos teóricos formalistas, ao falar sobre o procedimento artístico que caracteriza a linguagem literária e a maneira de percebê-la, menciona que "o objetivo da arte é dar a sensação do objeto como visão e não como reconhecimento; o procedimento da arte é o procedimento da singularização dos objetos", um meio de "experimentar o devir do objeto". O que importa é "a liberação do objeto do automatismo perceptivo". Para o autor, uma das finalidades da literatura é desautomatizar o modo de ver o mundo, restituindo às coisas o impacto e a particularidade que apresentam quando vistos pela primeira vez. Experiência estética que causa estranhamento, uma forma especial de ver os objetos e os acontecimentos cotidianos fora de seu contexto habitual.

Da mesma forma, o desejo de Barros - não só no poema citado como em toda a sua obra - é a fuga do lugar comum (da prosa) e das práticas metódicas, na tentativa de retorno à origem, conferindo um novo significado aos objetos e às palavras, sem enquadrá-las em nenhum código específico da língua. "Gostava de desnomear" (BARROS, 1993, p. 79), afirma o poeta. O que seria desconstruir para transformar. 
Então, tirar o pente de sua função costumeira de pentear e levá-lo a um outro universo, onde terá um contexto e um papel diferentes, contemplativo e sensível como uma flor ou planta. Nesse sentido, Chklovski reforça que a linguagem poética é capaz de causar maior estranhamento no âmbito linguístico e semântico, capaz de libertar do automatismo, muito distinto do empregado na prosa (obviamente sem desconsiderar o trabalho com as palavras). As construções de Barros evidenciam essa libertação da palavra, sugerida também pelo simbolismo, na qual os objetos são seus pretextos numa poesia metalinguística de um mundo particular (BENSE apud ${ }^{3}$ HAMBURGER 1986).

No âmbito da metalinguagem, para Rimbaud, a poesia moderna deveria refletir sobre a arte poética baseando-se em um conceito de poeta vidente, ou seja, "o objetivo do poetar é chegar ao desconhecido", perceber o invisível e ouvir o inaudível, trazer o não real e o não usual, conceitos que derivam de Baudelaire (FRIEDRICH, 1978, p. 62). Essa reflexão seria, então, a busca pela consciência primitiva, a poesia penetra no mistério vazio de uma realidade feita de pedaços. Ainda na primeira parte do livro de Barros, Uma didática da invenção, as referências ao seu fazer poético também são reveladas no poema a seguir:

VII

No descomeço era o verbo.

Só depois é que veio o delírio do verbo.

O delírio do verbo estava no começo, lá onde a

3 Bense, M. Experimentelle Schreibweisen (not. texto 17), Stuttgart, s/d apud Hamburger, Käte. A lógica da criação literária. Tradução: Margot P. Malnic. São Paulo: Perspectiva, 1986. criança diz: Eu escuto a cor dos passarinhos.

A criança não sabe que o verbo escutar não funciona

para cor, mas para som.

Então se a criança muda a função de um verbo, ele

delira.

E pois.

Em poesia que é voz de poeta, que é a voz de fazer

nascimentos -

O verbo tem que pegar delírio

(BARROS, 1993, p. 15).

Nota-se que o início do poema faz uma intertextualidade com a bíblia cristã na passagem da criação divina do mundo: "No princípio era o Verbo, e o Verbo estava com Deus, e o verbo era Deus." (João, 1:1). O poeta assume sua condição de vidente evidenciando seu processo criativo por meio de construções inovadoras. $\mathrm{O}$ prefixo des agora aparece no neologismo "descomeço", trazendo a conotação de um outro ou um falso começo, já que o verdadeiro se anuncia com o delírio do verbo, constituindo assim uma paródia ao distorcer a passagem bíblica. $\mathrm{O}$ sujeito lírico associa esse delírio aos dizeres de uma criança, que muda a função do verbo ao retirar as palavras de sua sintaxe convencional, remetendo assim a uma imagem sinestésica. Seria uma nova interpretação da realidade, criando novos sentidos para a vida, como cita Friedrich (1978, p. 16): "A poesia quer ser, ao contrário, uma criação auto-suficiente ( $\mathrm{sic}$ ), pluriforme na significação consistindo em um entrelaçamento de tensões de forças, as quais agem sugestivamente em estratos préracionais, mas também deslocam em vibrações as zonas de mistério dos conceitos".

Logo, o eu lírico se torna criança, como um ser livre, simples, criativo e que 
vê o mundo de uma perspectiva diferente, inocente e pura, capaz de brincar com a palavra. Assim como afirma o poeta, ele chega ao "criançamento das palavras": "As coisas que não tem nome são mais pronunciadas por crianças" (BARROS, 1993, Poema VI, p.13). Sua poesia vem exatamente do "[de]lírio" (remete a lírico, lírica) do verbo. Delirar significa entrar no mundo da imaginação, sair de si, do não comum, uma desconexão do sentido lógico, o que propõe a poética do autor. As mudanças do sentido das palavras aparecem do mesmo modo em outras passagens do livro, como: "Não tem altura o silêncio das pedras" (p.17), "Cheiroso som de asas vem do sul" (p.53), "Durmo na beira da cor" (p.67), “Um sabiá me aleluia" (p. 71) e "Ele me rã" (p.75). Os últimos versos do poema citado acima ainda lembram a voz do poeta (eu lírico) e o nascimento, como algo novo, [re]inventado, que surge a partir de suas transformações, remetendo também à criação e origem de sua poesia. É possível perceber que nessa passagem Barros reivindica mais uma vez sua condição de poeta vidente, penetrando no desconhecido além da realidade.

As diferentes sensações, as chamadas sinestesias, são mais um esforço para recuperar a linguagem original. Ao trabalhar com essas imagens, o poeta tenta representar o instante da percepção, de um movimento, sem levar em conta a inteligência ou a gramática. Manoel de Barros "escuta a cor dos passarinhos" assim como Baudelaire "aspira perfumes" ao mesmo tempo "fresco como carnes de crianças", "doces como oboés" e "verdes como as pradarias"; e Rimbaud vê nas vogais estranhas combinações de cores (GOMES, 1985, p. 17). Barros já dizia: “Eu gosto de fazer desenhos verbais de imagens" ${ }^{\prime 4}$. Essas figuras ganham vários sentidos e em diversos níveis. Logo, mais do que dizer uma verdade, o poeta cria uma realidade que possui a sua verdade, que diz algo sobre o mundo e sobre nós mesmos (PAZ, 1996).

Portanto, confirma-se os dizeres de Friedrich (1978, p.17): dentre as três maneiras nas quais se comportam a composição lírica - "sentir, observar, transformar - é esta última que domina na poesia moderna, em verdade, tanto no que diz respeito ao mundo como à língua".

No poema, Manoel de Barros também apresenta elevada consciência criadora, desenvolvendo uma dialética própria ao alterar as estruturas sintáticas e semânticas da língua, o que confirma que "toda poesia é obra de arte linguística" (STAIGER, 1975, p. 71) e ultrapassa todos os limites da lógica e da pura intenção comunicativa, é deslocamento, um transcender da linguagem. Ao estilo de Mallarmé, Barros não quer que a palavra fale mediante relações gramaticais, mas que irradie suas múltiplas possibilidades de sentido. "Como se ela tivesse acabado de nascer, para limpá-la das impurezas da linguagem cotidiana e devolvê-la ao seu sentido original", diz o poeta (BARROS, 1996, p. 310).

Na renúncia à coerência gramatical, lógica e formal, o poeta tem a palavra como material bruto e vai modificar, mais uma vez, sua semântica automatizada e engessada em novas possibilidades de sentido. "A palavra não tem um significado preciso. É um camaleão no qual se manifestam não somente nuances diversas, mas às vezes também colorações

\footnotetext{
4 Entrevista com Manoel de Barros. Palavra. Disponível: em: http://www.sesc.com.br/portal/site/palavra/dossie/ entrevista/entrevista $+\mathrm{com}+$ manoel + de + barros. Acesso em 19 jun. 2018.
} 
diferentes" (TYNIANOV, 1975b, p. 5). Ou ainda como pontua Paz (2012, p.22), a unidade poética só é captada no "trato nu com o poema".

Nas palavras de Barros, são atenuados o que Tynianov (1975a), outro formalista russo, chama de "indício fundamental" das palavras (sua unidade de categoria lexical), predominando os indícios secundários e flutuantes, que fogem ao significado habitual e ganham um sistema semântico particular, como na linguagem simbolista. Esse deslocamento do indício fundamental dá sempre margem à uma nova tensão semântica.

Com seu neologismo contraventor, a poesia de Barros se aproxima à prosa de Guimarães Rosa, que levou até as últimas consequências as possibilidades de criação da língua. Ao estilo Guimarães Rosa, o poeta afirma que encontrou a mesma "desobediência sintática e semântica" que o procurava, só assim seria possível "remendar outra feição para a natureza"5 e fugir do discurso automático. Ele não gostava de "palavra acostumada"6 e era preciso "germinar um idioleto"7, isto é, um novo dialeto específico. Por isso, convidou Rosa para participar de seu universo: "Levei o Rosa na beira dos pássaros que fica no meio da Ilha Linguística" (BARROS, 2002, p.33). E assim, ambos puderam ficar em "estado de palavra"8, compartilhando do mesmo desejo de 'enlouquecer o verbo' e tentando encontrar o grau zero ${ }^{9}$ da palavra, o momento de sua criação.

\footnotetext{
5 Entrevista com Manoel de Barros. Palavra. Disponível: em: http://www.sesc.com.br/portal/site/palavra/dossie/ entrevista/entrevista + com + manoel + de + barros. Acesso em 19 jun. 2018.

6 BARROS, M. de. Livro sobre nada. Rio de Janeiro: Record, 1997.

Retrato do artista quando coisa. Rio de Janeiro: Record, 2002, p. 29.

8 Ibidem, p. 33.

9 Termo citado pelo autor Luiz Henrique Barbosa no livro Palavras do chão: um olhar sobre a linguagem adâmica em Manoel de Barros. São Paulo: Annablume, 2003.
}

Para entrar nesse "estado de palavra", o poeta evidencia no verso IX sua poética da invenção:

IX

Para entrar em estado de árvore é preciso partir de

um torpor animal de lagarto às três horas da tarde, no mês de agosto.

Em dois anos a inércia e o mato vão crescer em

nossa boca.

Sofreremos alguma decomposição lírica até o mato

sair na voz.

Hoje eu desenho o cheiro das árvores (BARROS, 1993, p. 17).

No poema, Barros transfigura o estado habitual do homem ("estado de árvore") ao revelar uma metamorfose na qual ele ganha outra consciência e outra figura ao tomar o lugar de um animal, incorporando as características da natureza. Um ser racional se coloca em estado de inércia, isto é, de disponibilidade e relaxamento, e se transforma em outra criatura inconsciente, mas não volta ao estado de ignorância. A decomposição seria uma profunda mudança de estado, e o ser, no terreno fecundo lírico, floresce com outro saber e outra consciência, até ser capaz de criar e poetizar em um novo mundo totalmente sinestésico. Então, ecoam as palavras de Rimbaud "eu é outro", o sujeito não é o eu empírico, mas ganha outra força e outra voz. A poesia moderna se lança ao caos do inconsciente, para a visão do desconhecido. O "trabalhador técnico" (autor) e o "trabalhador poético" (eu lírico) encontram-se no verso, há uma desumanização, na qual o "eu" é o resultado da autotransformação do poeta em uma multiplicidade dissonante de vozes. Por isso, o verso ganha a primeira 
pessoa do plural 'sofreremos'. E, como propõe Mallarmé, "sou agora impessoal", o homem, enquanto intelecto e linguagem, é o "Ser absoluto", o "Nada", que convoca a língua e encontra nela sua realização (FRIEDRICH, 1978, p.62 et seq.). O artista não é mais uma pessoa particular, porém uma inteligência que poetiza, como operador da língua, e vê as mais diversas coisas e seres se transmutarem em magia poética.

A segunda parte de $O$ livro das ignorãças, intitulada Os deslimites da palavra, começa com um texto que explica os versos a seguir:

\section{Explicação desnecessária}

Na enchente de 22, a maior de todas as enchentes

do Pantanal, canoeiro Apuleio vogou três dias e três noites

por cima das águas, sem comer sem dormir - e teve

um delírio frásico. A estórea aconteceu que um dia,

remexendo papéis na Biblioteca do Centro de Criadores

da Nhecolândia, em Corumbá, dei com um pequeno

Caderno de Armazém, onde se anotavam compras fiadas

de arroz feijão fumo etc. Nas últimas folhas do caderno

achei frases soltas, cerca de 200 .

Levei o manuscrito para

casa. Lendo as frases com vagar imaginei que o desolo a

fraqueza e o medo talvez tenham provocado, no canoeiro, uma ruptura com a normalidade. Passei anos penteando

e desarrumando as frases. Desarrumei o melhor que pude.

O resultado ficou esse. Desconfio que, nesse caderno, o canoeiro voou fora da asa

(BARROS, 1993, p. 31).
Novamente, o poeta evoca o sentido das origens e da criação, relacionando a origem da língua (ou o antes da língua) ao seu fazer poético e à criação do mundo. Refere-se a uma enchente como se fosse o dilúvio bíblico, com duração de três dias e três noites (o mesmo tempo que Jesus demorou para ressuscitar, segundo as crenças cristãs). O homem volta ao seu começo e também tem um delírio de frases, assim como no poema VII ("No descomeço era o verbo. Só depois é que veio o delírio do verbo."). A enchente de 22 transforma o personagem em poeta, há uma ruptura com a normalidade. Logo, o autor passa a "pentear e desarrumar as frases", fazendo referência ao seu ato de criação poética, e o "voar fora da asa" seria sua própria poesia. Os poemas dessa parte do livro tornam-se, então, o diário de bordo do personagem Apuleio, com versos que remetem à origem: "Eu sei das iluminações do ovo" (p.41); "Hão de nascer tomilhos em meus sinos" (p.61); "Engastado no meu verbo está seu ninho" (p.63); "Só penso coisas com efeito de antes. Nas minhas memórias enterradas" (p.65); "O azul me descortina para o dia. (...) Vejo um ovo de anu do outono" (p.67).

A obra de Manoel de Barros ainda apresenta certa obscuridade, estranhamento, descontinuidade em sua fuga da realidade e das coisas comuns, é a poesia sobre nada, características típicas da modernidade e predominantes também na obra de poetas simbolistas como Mallarmé, que aperfeiçoou as concepções propostas desde Baudelaire e Rimbaud. De acordo com Gomes (1985, p.22), verifica-se, principalmente em Mallarmé, a preocupação fundamental com a linguagem, a fim de romper com o modo explícito e direto de expressão. Ele visava 
“não só captar o misterioso, mas também o inefável, os instantes passageiros, os estados íntimos que mudam a cada momento da experiência", tal qual fez Barros. Obviamente, essa obscuridade não é tão percebida e tão emblemática como a de Mallarmé, não está no oculto, mas na fuga ao racional, na paródia de sentido e seus múltiplos significados, na sua obra anti-intelectualista e na violação das regras tradicionais, que levam a um estilo diferenciado.

Nesse aspecto, voltando ao livro, no terceiro dia de viagem de Apuleio, com o poema 3.5, pode-se perceber algumas dessas características:

\section{5}

A luz faz silêncio para os pássaros, - eu escuto esse escândalo! Um perfume vermelho me pensou. (Eu contamino a luz do anoitecer?) Esses vazios me restritam mais. Alguns pedaços de mim já são desterro.

(É a sensatez que aumenta os absurdos?) De noite bebo água de merenda. Me mantimento de ventos.

Descomo sem opulências...

Desculpe a delicadeza

(BARROS, 1993, p.69).

Percebe-se que a poesia de Barros se mostra sem obviedades, seu poetar chega a ser enigmático, afastando-se da compreensão limitante e acostumada. Outra vez, as palavras são tiradas de sua semântica comum e as coisas recebem vida, como a luz que ganha função sonora e faz silêncio, o perfume que pensa ou os ventos que servem de mantimentos. As metáforas construídas contribuem não apenas como um ornamento do discurso, mas é um recurso vivo, criado, provocando ainda maior tensão narrativa e extensão de sentido (RICOEUR, 1987). Logo, a poesia tem sua base na realidade, mas a utiliza como expansão, desmembramento, tensões em contrastes, passando ao irreal. Essas características atribuem maior carga de significação à linguagem, como afirma Barbosa (1986, p. 26): “O poeta, ao ler a realidade através do poema, constrói um espaço em que a linguagem não oferece transparência imediata: a sua univocidade está limitada pelo jogo possível das imagens utilizadas".

Portanto, o estranhamento e a descontinuidade, características da lírica moderna, apesar de exigirem maior compreensão e cooperação textual do leitor, geram o fascínio de uma nova linguagem e uma nova forma, "é uma urdidura do estranho, insondável e extasiante" (FRIEDRICH, 1978, p. 63).

Ao final da segunda parte do livro, o verso "um sabiá me aleluia" indica que Apuleio, enfim, termina sua viagem e chega à terra firme, numa espécie de novo descobrimento da terra e de si próprio, que agora é um ser alterado por seu "delírio frásico", já é um poeta. Chega à terceira e última parte do livro, onde Manoel de Barros celebra seu Mundo pequeno, apresentando os pequenos seres, os restos e as "nadezas".

\section{1}

O mundo é pequeno, Senhor.

Tem um rio e um pouco de árvores.

Nossa casa foi feita de costas para o rio.

Formigas recortam roseiras da avó.

No fundo do quintal há um menino e suas latas. maravilhosas.

Seu olho exagera o azul.

Todas as coisas deste lugar já são comprometidas com aves. 
Aqui, se o horizonte enrubesce um pouco, os besouros pensam que estão no incêndio.

Quando o rio está começando um peixe,

Ele me coisa

Ele me rã

Ele me árvore

De tarde um velho tocará sua flauta para inverter os ocasos (BARROS, 1993, p. 75).

Assim como a poesia de Baudelaire que trazia os vales, as flores, os caracóis, a carniça e os ocasos, a de Mallarmé, que se valia das coisas simples (vasos, leques, espelhos), e a de Rimbaud, com sua diversidade de elementos, que iam dos bosques e das estradas do campo aos vagabundos e prostitutas (belo e feio), Manoel de Barros também apresenta o simples nas miudezas, nas coisas, nos seres e nos elementos da natureza, misturando beleza à semântica do precário, da grandeza do ínfimo, dos restos e de suas 'nadezas'. Toma os rios, as plantas, as formigas, as lagartixas, as aves, os besouros, as pedras, as rãs e todas as 'pequenezas' como matéria-prima para a construção de seus versos. O que pode ser observado, especificamente, no poema $I V$, voltando à primeira parte do livro:

IV

No Tratado das Grandezas do Ínfimo estava escrito:

Poesia é quando a tarde está competente para dálias.

É quando

Ao lado de um pardal o dia dorme antes.

Quando o homem faz sua primeira lagartixa.

É quando um trevo assume a noite

E um sapo engole as auroras

(BARROS, 1993, p. 13).
Para o poeta, "poesia é a virtude do inútil - o inútil só presta para poesia, mais nada"10. O autor reconhece a grandeza, a potencialidade bela e criativa dos seres ínfimos, que ganham novo significado. Esse nada é, ao mesmo tempo, o absoluto, a verdade na qual se eliminam as 'casualidades' empíricas, e isso passa pelo absurdo, pela renúncia ao habitual na busca pelo ideal. Mallarmé dizia "depois de ter encontrado o Nada, encontrei a beleza" (apud FRIEDRICH, 1978, p. 116). Para ele, o conceito do Nada (do niilismo), seria "uma consequência do espírito que esvazia todo o real para satisfazer sua liberdade criativa (...) uma poesia em que a própria linguagem torne presente o Nada", mediante o aniquilamento da realidade (ibidem, p.125). Da mesma maneira que Mallarmé, Barros torna seus seres enigmáticos, voltando-os às suas origens e imprimindo-lhes o modo profundo do ser absoluto, e consegue, assim, obter o mistério essencial das coisas familiares "ele me coisa, ele me rã, ele me árvore"; "É quando um trevo assume a noite e um sapo engole as auroras"). A poesia ultrapassa o real pela beleza da linguagem, criando imagens que reproduzem a pluralidade de sentido da mesma realidade, trazendo-Ihe unidade sinestésica (PAZ, 1996). "Eis porque a poesia é lírica: o canto do mistério com palavras e imagens, cuja recepção faz a alma vibrar, mesmo que esta esteja conduzida ao desconhecido" (FRIEDRICH, 1978, p. 97).

Por todo o restante dos poemas da parte final de O livro das ignorãças, é possível ver frases que indicam essa poética das pequenas coisas e do nada: "As coisas que não existem são mais

\footnotetext{
${ }^{10}$ Citado no filme Só dez por cento é mentira - a desbiografia oficial de Manoel de Barros, 2008. Disponível em: http:// www.sodez.com.br/. Acesso em: 23 jun. 2018.
} 
bonitas" (p. 77); "Sempre nos pareceu feito de restos" (p. 79); "Caçador de rãs entardecidas", "Sonora voz de uma concha", "Borboletas de franjas amarelas são fascinadas por dejectos", "Nascera engrandecido de nadezas" (p. 81); "Esses lagartos curimpãpãs têm índole tropical (p. 83). As categorias negativas e a tentativa de reconstrução também são percebidas nas palavras com o prefixo des: desnomear, deslimites e descomeço, cada uma ganhando novo contexto, como já explorado anteriormente. Para Barbosa (1986), essa negatividade na poesia moderna e contemporânea marcam os espaços não preenchidos da tradição literária: "A poesia já não é, portanto, arte da linguagem: o seu módulo passa a ser anti por excelência. Negando-se, para afirmar o espaço que ficou por preencher. O espaço tolhido pelos escolhos de uma tradição que se tenta recusar, mas que se infiltram traiçoeiramente pelas frestas da própria linguagem (BARBOSA, 1986, p. 108-109)".

Já em relação à estética de Barros, tomando como base os estudos de Tynianov (1975a, 1975b) sobre o sentido e os elementos construtivos da poesia, percebe-se que seus poemas são apresentados em versos livres. Essa concepção acústica do verso resulta em um discurso dinamizado, de complexidade rítmica, o que se congrega ainda na transgressão do automatismo. Não há um complexo métrico de rimas e estrofes estabelecidas, mas diversidade da forma, na qual cada verso se soma ao outro em uma estrutura orgânica de sentido. Essa mistura de sistemas diferentes ganha nova articulação sonora, o que resulta em uma espécie de grupo rítmico, união de forma e conteúdo próprios com extraordinária ousadia em sua narrativa.
Outro aspecto que merece ser abordado com relação à estética são as referências à natureza pantaneira, que serve como pano de fundo para as criações de Barros. O próprio poeta alertava que não era poeta de paisagem, mas inventava seu próprio Pantanal:

A minha poesia é fertilizada pelo sol, pelas águas, pelo chão do Pantanal, é fertilizada, não me serve a mim para descrever paisagens, poesia não é um fenômeno de paisagem, é um fenômeno de linguagem. Nasci no Pantanal, tenho amor pelo Pantanal, mas sou um poeta da palavra [...] não sou poeta ecológico, não quero fazer folclore, não quero expressar costumes, não sou historiador, eu sou poeta. Poeta é um ser que inventa. Eu invento meu Pantanal (Filme Só dez por cento é mentira - a desbiografia oficial de Manoel de Barros, 2008 ${ }^{11}$ ).

Assim, o espaço lhe servia como base para trabalhar sua poética inventiva e para se transbordar em sua linguagem entre os seres mais miúdos e insignificantes.

Diante de todo o exposto, é possível notar em $O$ livro das ignorãças, e por toda a obra de Manoel de Barros, que seu projeto mais nítido e inovador foi, portanto, o trabalho com a linguagem. O poeta pantaneiro caminhou pelas velhas e conhecidas palavras, retirando-as de seu significado primeiro e seu discurso comum. Barros restitui à linguagem sua liberdade na fuga da lógica e das regras preestabelecidas, que revelou um estilo completamente original em sua poesia. Ao imprimir personalidade nas palavras, renova o ato criativo, arejando o cânone literário com sua percepção visual e

\footnotetext{
${ }_{11}$ Disponível em: http://www.sodez.com.br. Acesso em: 23 jun. 2018.
} 
sinestésica. $\mathrm{O}$ autor conseguiu tirar lirismo das miudezas do cotidiano, o que favorece a "disposição anímica"12 e a transcendência do poema. Seus versos trazem um novo canto, uma nova sonoridade, tal qual o poeta mesmo aprendeu: "eu me lembro que aprendi nos gorjeios a maneira de dar canto aos versos"13. Uma melodia que fala das coisas, seres e nadas, uma música dissonante. Assim, como afirma Paz (2012, p. 21), "o poema é um caracol onde ressoa a música do mundo", onde ressoa Manoel de Barros com seu "dialeto coisal, larval, pedral14".

\section{Referências}

BARBOSA, João Alexandre. As ilusões da modernidade. São Paulo: Perspectiva, 1986.

BARBOSA, Luiz Henrique. Palavras do chão: um olhar sobre a linguagem adâmica em Manoel de Barros. São Paulo: Annablume, 2003.

BARROS, M. de. Gramática expositiva do chão. Poesia quase toda. Rio de Janeiro: Civilização Brasileira, 1996.

BARROS, M. de. Livro sobre nada. Rio de Janeiro: Record, 1997.

BARROS, M. de. O livro das ignorãças. 10. ed. Rio de Janeiro: Record, 1993.

BARROS, M. de. Retrato do artista quando coisa. Rio de Janeiro: Record, 2002.

CHKLOVSKI, V. A arte como procedimento. In: EIKHENBAUNM, B. et al. Teoria da literatura:

${ }^{12}$ Conceito de Emil Staiger, na qual o sujeito lírico é o mesmo objeto de seu discurso. A 'disposição' não está dentro nós, mas fora, não diante das coisas, mas nelas e elas em nós. Assim, o leitor deve estar receptivo ao poema, no mesmo estado lírico do autor para adentrar também na obra.

${ }^{13}$ Entrevista com Manoel de Barros. Palavra. Disponível: em: http://www.sesc.com.br/portal/site/palavra/dossie/ entrevista/entrevista $+\mathrm{com}+$ manoel + de + barros. Acesso em 19 jun. 2018.

${ }^{14}$ Barros, M. de. O guardador de águas. São Paulo: LeYa, 2013, p. 42 formalistas russos. Tradução de A. M. R. Filipouski et al. Porto Alegre: Globo, 1973. p. 39-56.

FRIEDRICH, Hugo. A estrutura da lírica moderna. Tradução de Marise M. Curioni. Tradução das poesias: Dora F. da Silva. São Paulo: Duas Cidades, 1978.

GOMES, Álvaro Cardoso. A estética simbolista. Seleção de textos, comentários, introdução geral, bibliografias e índice de nomes. Tradução dos textos antologiados de Eliane Fittipaldi Pereira. São Paulo: Cultrix, 1985.

HAMBURGER, Käte. A lógica da criação literária. Tradução de Margot P. Malnic. São Paulo: Perspectiva, 1986.

PAZ, Octávio. Introdução. Poema e poesia. In: PAZ, Octávio. O arco e a lira. Tradução de Ari Roitman e Paulina Wacth. São Paulo: Cosac Naify, 2012.

PAZ, Octávio. Signos em rotação. Tradução de Sebastião Uchoa Leite. 3. ed. São Paulo: Perspectiva, 1996.

RICOEUR, Paul. A metáfora e o símbolo. In: RICOEUR, Paul. Teoria da interpretação. Tradução de Artur Morão. Lisboa: Ed. 70, 1987.

TYNIANOV, luri. O problema da linguagem poética I: o ritmo como elemento constitutivo do verso. Tradução de Maria José Azevedo Pereira e Caterina Barone. Rio de Janeiro: Tempo Brasileiro, 1975a.

TYNIANOV, luri. O problema da linguagem poética II: o sentido da palavra poética. Tradução de Maria José Azevedo Pereira e Caterina Barone. Rio de Janeiro: Tempo Brasileiro, 1975b.

Recebido em: 19/11/2018

Aceito em: 14/01/2019

Publicado em: 00/05/2019

\section{Autora:}

GEYSIANE ANDRADE

Mestranda do Programa de Pós-Graduação em Letras na área de concentração Escrita Criativa da Pontifícia Universidade Católica do Rio Grande do Sul (PUCRS), Porto Alegre/RS. O presente trabalho foi realizado com apoio da Coordenação de Aperfeiçoamento de Pessoal Nível Superior - Brasil (CAPES) Código de financiamento 001.

Orcid: http://orcid.org/0000-0002-6711-1691

e-mail: geysiaandrade@gmail.com 